Professor Yuan-Shyi Peter Chiu, PhD

Han-Ying Chen, MS

Dept. of Industrial Engineering \& Management

Chaoyang University of Technology, Taichung City 413, Taiwan

Assistant Professor Tiffany Chiu

Anisfield School of Business, Ramapo College of New Jersey

Mahwah, NJ 07430, USA

Professor Singa Wang Chiu*, PhD

Dept. of Business Administration, Chaoyang University of Technology

* Corresponding author: E-mail: swang@ cyut.edu.tw (SW Chiu)

\title{
INCORPORATING FLEXIBLE FABRICATION RATE AND RANDOM SCRAP INTO A FPR-BASED SUPPLY-CHAIN SYSTEM
}

\begin{abstract}
Operating in highly competitive world markets, managers of the present-day manufacturing firms always look for potential means to reduce fabrication cycle length, assure product quality, and trim down shipping expenses in their intra-supply chains. To help accomplish these operation goals, this paper examines a finite production rate (FPR)-based supply-chain system with flexible fabrication rate, random scrap, and multi-ship policy. In which, the manufacture rate in the proposed system is assumes to be adjustable, scrap items are identified and discarded, and fixed-quantity multi-shipment of the finished lot are delivered at a fixed interval of time during production downtime of a cycle. The objective is to determine the optimal lot size and number of shipments that minimize the expected total system costs. Mathematical modeling and Hessian matrix equations are applied to resolve the problem. Applicability of the results is verified via a numerical example. Various desirable system performances are revealed and become accessible to support managerial decision makings.

Key words: Operations Research, Production management, Supply chain, Finite production rate, Flexible fabrication rate, Scrap, Multiple shipments
\end{abstract}

JEL classifications: C02, C44, M11, C61

\section{Introduction}

A finite production rate (FPR)-based supply chain system with flexible fabrication ate, random scrap, and multi-shipment is investigated in this paper. The classic FPR model [1] considers constant manufacture rate, perfect product quality, and continuous stock issuing policy; and it utilized mathematical modeling and 
Yuan-Shyi Peter Chiu, Han-Ying Chen, Tiffany Chiu, Singa Wang Chiu

differential calculus to decide the most economic batch size in a replenishment cycle. However, in present-day's manufacturing firms, with the intention of reducing fabrication cycle length or leveling machine loading, increase of manufacture rate on equipment can be one of the practical operating options. Buzacott and Ozkarahan [2] studied a two-product single-machine and a two-product two-machine production scheduling problem, wherein the demand is constant and setup cost exists on the two-product single-machine option. It was also assumed that for each product the manufacture rate is adjustable. Their research results revealed that (1) the characteristic of the optimal schedule is not to have any idle time in between runs; (2) if calculation of holding cost is based on average inventory, then on the bottleneck stage maximal manufacture rate always applies to one product; conversely, if maximal inventory constraint exists, then in the single-machine neither product should be fabricated at maximal rate. Gallego [3] examined an economic lot scheduling problem with reduction of the manufacture rate from its standard rate, to stay away from a fast growth of inventories and minimize a sharp lower bound on average stock holding cost. A time-varying heuristic was employed to obtain a near-optimal schedule that helps to decide the item's manufacture rate, order intervals, and lower bound of average holding cost. The research result also indicated that extra savings can be gained if rates can be reduced by inserting random idle times between fabricating successive units of the same item without extra setup costs involved. Eynan [4] investigated a multi-product single machine economic lot scheduling problem, wherein different manufacture rates are permitted in a production run. The optimal common cycle solution to the problem was derived, and lower bounds on savings as compared to conventional approach were also explored and revealed. Glock [5] studied the effect of a variable fabrication rate on maximal stock level and total system costs in a single-product single facility manufacturing system with inventory issuing at discrete time intervals. Several models for the cases of equal- and unequal-sized batch shipments were constructed and investigated. A numerical example was provided to demonstrate that deviating from the standard manufacture rate may reduce stock holding cost and hence lead to savings in total system cost. Farzam Rad et al. [6] considered a multi-product multi-period production planning problem, wherein demand rate, process time, and setup time of every product in each period are of probabilistic nature. Simulation approach was used to help decide the system response rate for various numbers of manufacture rates in different periods, and the optimal response was obtained as well by simulated annealing algorithm. Extra papers that explored various aspects of manufacturing systems with diverse production rates can also be referred to [7-9].

Different from the assumption of perfect product quality in classic FPR model, most real production systems randomly produce scrap items due to a variety of unforeseen issues. Schwaller [10] considered an economic order quantity (EOQ) model incorporating fixed and variable inspection costs in order to find and remove defective products in incoming lots. Cheung and Hausman [11] jointly decided the safety stock and preventive maintenance policies for a manufacturing system that 
Incorporating Flexible Fabrication Rate and Random Scrap Into A FPR-Based Supply-Chain System

is subject to stochastic machine breakdown. Trade-off between investing in these policies were studied and discussed. Both deterministic and exponential repair time distributions were assumed and investigated and the optimal conditions under either one or both policies are derived accordingly. Ritvirool and Ferrell [12] explored the effect of quality issues on a single-vendor, single-buyer procurement system, wherein $(\mathrm{Q}, \mathrm{r})$ policy is used by the buyer and fabrication batch size based on make-to-order policy is utilized by the producer. Existence of defective items along with cost of quality is assumed in the producer side. The effect of quality issues on the optimal order quantity, reorder point, and safety stock level were explored. Additional papers that studied different features of manufacturing systems with defective rates and their consequently corrective actions can be referred to [13-16].

In modern transnational firms, joint determination of the optimal fabrication and delivery policies is one of the operating goals that help minimize the overall operation costs. Kohli and Park [17] studied the joint ordering policies with the purpose of reducing transactions cost for multiple products that sold by single seller to multiple customers. In their study, the efficient lot sizes were found to be independent of prices, and were supported by a range of average-unit prices that allow savings on transactions costs between buyer and seller in all locations. In addition, they found out that the product bundling is in favor of efficient joint orders across products. Sarker and Khan [18] determined the optimal lot size for a manufacturing system with a periodic shipping plan. In their proposed system, an ordering policy for raw materials procurement was proposed to meet the requirements of a production facility. Raw materials in lot was processed and transformed into finished products, then transported to meet product demand of buyers at fixed interval of time. A cost function for the proposed manufacturingdelivery integrated system was built and analyzed. A solution procedure was used to help decide the optimal ordering policy for procurement of raw materials and optimal fabrication lot size that to minimize the total system costs. Giri and Chakraborty [19] developed a single-vendor single-buyer coordinated supply chain system, wherein the products in lot were fabricated by the vendor and distributed to buyer in equal shipments. They assumed that the fabrication process may randomly shift from an in-control state to an out-of-control state and generates defective items. The screening process was implemented by the buyer upon receipt of each replenishment lot, and it was further assumed the buyer's inventory deteriorated at a constant rate over time. By minimizing the average cost of proposed system, the optimal vendor-buyer coordinated policy is decided, and through numerical example, the significant cost savings as compared to that in non-coordinated system was obtained. Other papers that addressed a variety of supply-chain systems with multiple deliveries can also be referred to [20-23]. In brief, with the intention of helping production managers to reduce fabrication cycle time, assure product quality, and cut down transportation expenses, this study explores a FPR-based 
Yuan-Shyi Peter Chiu, Han-Ying Chen, Tiffany Chiu, Singa Wang Chiu

supply-chain system with flexible fabrication rate, random scrap, and multi-shipment policy. Since little attention was paid to this field, the present study aims at filling the gap.

\section{The proposed FPR-based supply-chain system}

A FPR-based supply-chain system with adjustable fabrication, random scrap, and multiple shipments is explored. The parameters used and their definitions are presented in Nomenclature (see Appendix A). Consider that an adjustable rate $P_{\mathrm{A}}$ units per year is adopted by the proposed system to satisfy a demand rate $\lambda$ units for a particular product. Because of this adjusted higher fabrication rate, manufacturing unit cost $C_{\mathrm{A}}$ and setup cost $K_{\mathrm{A}}$ also increase. The following are the relationships between $P_{\mathrm{A}}, C_{\mathrm{A}}$, and $K_{\mathrm{A}}$ and their corresponding standard parameters:

$$
\begin{aligned}
& P_{\mathrm{A}}=\left(1+\alpha_{1}\right) P \\
& C_{\mathrm{A}}=\left(1+\alpha_{3}\right) C \\
& K_{\mathrm{A}}=\left(1+\alpha_{2}\right) K
\end{aligned}
$$

where $\alpha_{1}$ denotes the adjusted percentage in annual fabrication rate, $\alpha_{2}$ and $\alpha_{3}$ represent the increase percentages in cost, and $P, C$, and $K$ are the standard (unadjusted) annual fabrication rate, unit and setup costs, respectively. During uptime $t_{1 \mathrm{~A}}$ of a production cycle (see Figure 1), an $x$ percentage of scrap products is assumed to be randomly produced at a rate $d_{\mathrm{A}}$ as follows:

$$
d_{\mathrm{A}}=x P_{\mathrm{A}}=x\left(1+\alpha_{1}\right) P
$$

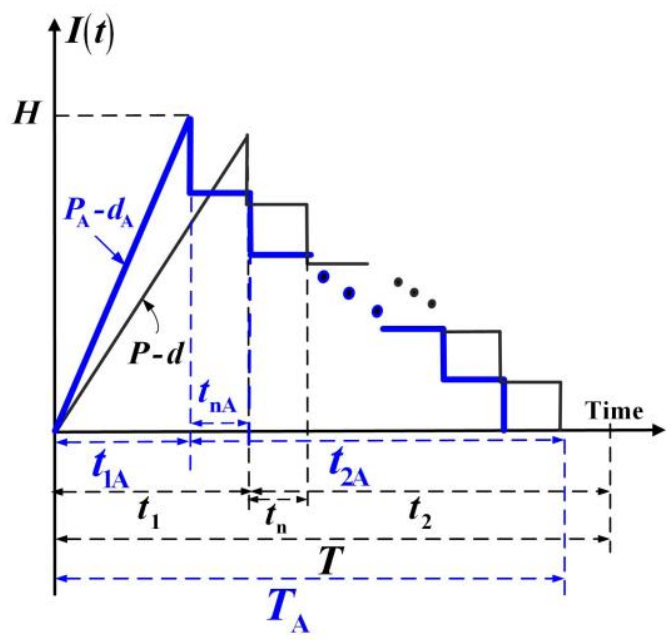

Figure 1. Status of inventories in the proposed FPR-based supply-chain system (in blue) compared to that in traditional FPR model (in black)

Total scrap products in the end of $t_{1 \mathrm{~A}}$ are $d_{\mathrm{A}} t_{1 \mathrm{~A}}$ or $x Q$ (see Figure 2), they are discarded when uptime $t_{1 \mathrm{~A}}$ finishes, at unit disposal $\operatorname{cost} C_{\mathrm{S}}$. It is also assumed that 
Incorporating Flexible Fabrication Rate and Random Scrap Into A FPR-Based Supply-Chain System

no shortages are allowed, thus, $\left(P_{\mathrm{A}}-d_{\mathrm{A}}-\lambda\right)$ must be greater than zero.

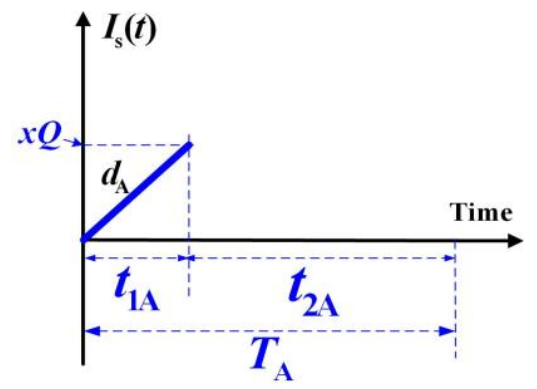

Figure 2. Status of scrap items in proposed FPR-based supply-chain system

By observing Figure 1, the production cycle time $T_{\mathrm{A}}$, uptime $t_{1 \mathrm{~A}}$, distribution time $t_{2 \mathrm{~A}}$, batch size $Q$, and maximal level of finished products $H$ in a cycle, can be observed as follows:

$$
\begin{gathered}
T_{\mathrm{A}}=t_{1 \mathrm{~A}}+t_{2 \mathrm{~A}}=\frac{Q(1-x)}{\lambda} \\
t_{1 \mathrm{~A}}=\frac{Q}{P_{\mathrm{A}}}=\frac{Q}{\left(1+\alpha_{1}\right) P} \\
t_{2 \mathrm{~A}}=T_{\mathrm{A}}-t_{1 \overline{\overline{\mathrm{A}}}} \frac{Q(1-x)}{\lambda}-\frac{Q}{\left(1+\alpha_{1} P\right.} \\
Q=P_{\mathrm{A}} t_{1 \mathrm{~A}}=\left[\left(1+\alpha_{1}\right) P\right] t_{1 \mathrm{~A}} \\
H=\left(P_{\mathrm{A}}-d_{\mathrm{A}}\right) t_{1 \mathrm{~A}}
\end{gathered}
$$

Upon completion of production process, $n$ fixed quantity installments of finished products are distributed to customer, at a fixed interval of time in $t_{2 \mathrm{~A}}$ (see Figure 3 ). The interval of time $t_{\mathrm{nA}}$ between two consecutive shipments and number of finished products per shipment $D$, are as follows:

$$
\begin{aligned}
t_{\mathrm{nA}} & =\frac{t_{2 \mathrm{~A}}}{n} \\
D & =\frac{H}{n}
\end{aligned}
$$

In downtime $t_{2 \mathrm{~A}}$, total inventories (Figure 3) are as follows [24]:

$$
\left(\frac{1}{n^{2}}\right)\left(\sum_{i=1}^{n-1} i\right) H t_{2 \mathrm{~A}}=\left(\frac{n-1}{2 n}\right) H t_{2 \mathrm{~A}}
$$

Status of stocks at customer's side in any given cycle is illustrated in Figure 4. In the end of each time interval $t_{\mathrm{nA}}$ (after demand $\lambda t_{\mathrm{nA}}$ is met) the leftover stocks $I$ is as follows:

$$
I=D-\lambda t_{\mathrm{nA}}
$$




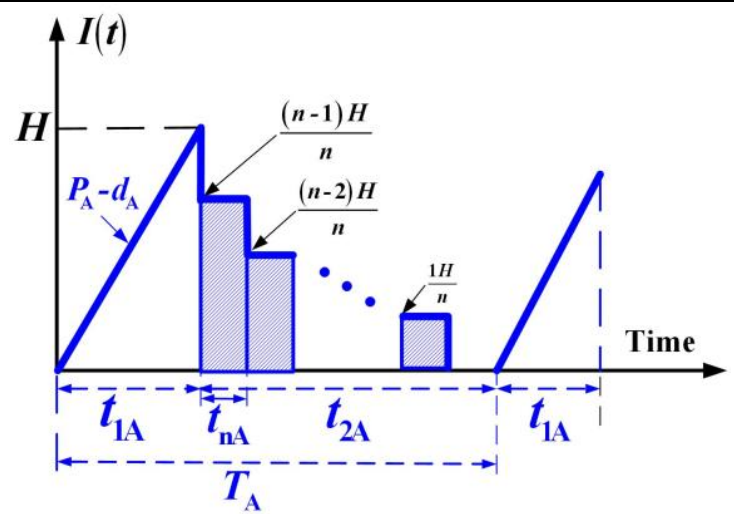

Figure 3. Status of finished products during $t_{2 \mathrm{~A}}$ in proposed system

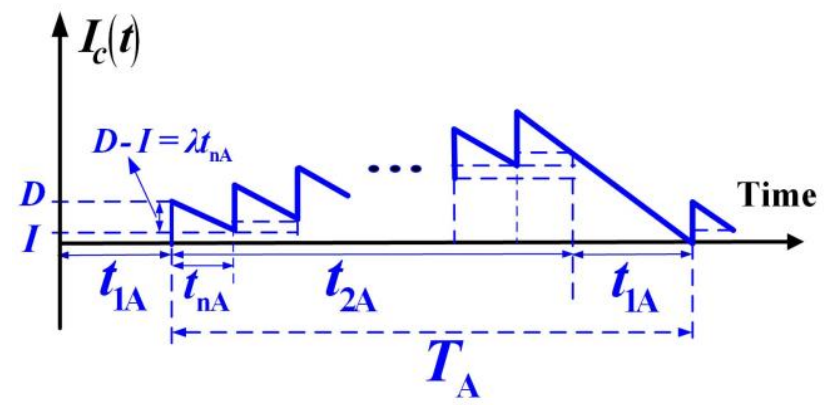

Figure 4. Status of stocks at customer's side in a given cycle in proposed system

In any production cycle, one can obtain total inventories at customer's side (Fig. 4) are as follows:

$$
\frac{n(n-1)}{2} I t_{n \mathrm{~A}}+n\left(D-\frac{\lambda t_{n \mathrm{~A}}}{2}\right) t_{n \mathrm{~A}}+\frac{n I}{2}\left(t_{1 \mathrm{~A}}\right)=\frac{1}{2}\left[\frac{H t_{2 \mathrm{~A}}}{n}+T_{\mathrm{A}}\left(H-\lambda t_{2 \mathrm{~A}}\right)\right]
$$

Overall cost per cycle of the proposed FPR-based supply-chain system includes the setup cost, variable fabrication and disposal costs, fixed and variable distribution costs, holding costs of finished and scrap products in uptime $t_{1 \mathrm{~A}}$, holding cost for products in distribution time $t_{2 \mathrm{~A}}$, and stock holding cost at customer's side in the cycle. Therefore, $T C(Q, n)$ is

$$
\begin{aligned}
T C(Q, n) & =K_{\mathrm{A}}+C_{\mathrm{A}} Q+C_{\mathrm{S}}(x Q)+n K_{1}+C_{T} Q+h\left[\frac{H+d_{\mathrm{A}} t_{1 \mathrm{~A}}}{2}\left(t_{1 \mathrm{~A}}\right)\right] \\
& +h\left(\frac{n-1}{2 n}\right) H t_{2 \mathrm{~A}}+\frac{h_{2}}{2}\left[\frac{H t_{2 \mathrm{~A}}}{n}+T_{\mathrm{A}}\left(H-\lambda t_{2 \mathrm{~A}}\right)\right]
\end{aligned}
$$

Substitute $K_{\mathrm{A}}, C_{\mathrm{A}}, P_{\mathrm{A}}$, and $d_{\mathrm{A}}$ in Eq. (15), $T C(Q, n)$ becomes 
Incorporating Flexible Fabrication Rate and Random Scrap Into A FPR-Based Supply-Chain System

$$
\begin{aligned}
T C(Q, n) & =\left(1+\alpha_{2}\right) K+\left(1+\alpha_{3}\right) C Q+C_{\mathrm{S}} x Q+n K_{1}+C_{T} Q+h\left(\frac{n-1}{2 n}\right) H t_{2 \mathrm{~A}} \\
& +h\left[\frac{H+x\left[\left(1+\alpha_{1}\right) P\right] t_{1 \mathrm{~A}}}{2}\left(t_{1 \mathrm{~A}}\right)\right]+\frac{h_{2}}{2}\left[\frac{H t_{2 \mathrm{~A}}}{n}+T_{\mathrm{A}}\left(H-\lambda t_{2 \mathrm{~A}}\right)\right]
\end{aligned}
$$

Further replace $H, t_{1 \mathrm{~A}}, t_{2 \mathrm{~A}}$, and $T_{\mathrm{A}}$ with the right-hand side results from Eqs. (5) to (7) and (9) in Eq. (16), and use the expected values of $x$ to take its randomness into account, and with extra derivations, $E[T C U(Q, n)]$ turns into the following:

$$
\begin{array}{r}
E[T C U(Q, n)]=\frac{E[T C(Q, n)]}{E\left[T_{\mathrm{A}}\right]}=\lambda\left[\left(1+\alpha_{3}\right) C E_{0}+C_{S} E_{1}\right]+\frac{\left[\left(1+\alpha_{2}\right) K\right] \lambda E_{0}}{Q}+\frac{\lambda n K_{1} E_{0}}{Q}+C_{T} \lambda \\
+\frac{h Q(1-E[x])}{2}+\frac{h \lambda Q E_{1}}{2\left(1+\alpha_{1}\right) P}+\frac{Q\left(h_{2}-h\right)}{2 n}\left[(1-E[x])-\frac{\lambda}{\left(1+\alpha_{1}\right) P}\right]+\frac{h_{2} Q}{2}\left[\frac{\lambda}{\left(1+\alpha_{1}\right) P}\right]
\end{array}
$$

where

$$
E_{0}=\frac{1}{1-E[x]} ; E_{1}=\frac{E[x]}{1-E[x]}
$$

\section{Deriving the optimal lot size and number of deliveries per cycle}

Apply the Hessian matrix equations [25], and we find the following (refer to Appendix B for details):

$$
\left[\begin{array}{ll}
Q & n
\end{array}\right] \cdot\left(\begin{array}{ll}
\frac{\partial^{2} E[T C U(Q, n)]}{\partial Q^{2}} & \frac{\partial^{2} E[T C U(Q, n)]}{\partial Q \partial n} \\
\frac{\partial^{2} E[T C U(Q, n)]}{\partial Q \partial n} & \frac{\partial^{2} E[T C U(Q, n)]}{\partial n^{2}}
\end{array}\right) \cdot\left[\begin{array}{l}
Q \\
n
\end{array}\right]=\frac{2\left[\left(1+\alpha_{2}\right) K\right] \lambda E_{0}}{Q}>0
$$

Since $\alpha_{2}, K, \lambda, E_{0}$, and $Q$ are all positive, so Eq. (18) results positive. Therefore, $E[T C U(Q, n)]$ is convex for all $Q$ and $n$ different from zero. To find the optimal $Q^{*}$ and $n^{*}$, we set both first partial derivatives of $E[T C U(Q, n)]$ with respect to $Q$ and $n$ equal to 0 , and solve the linear system as follows:

$$
\begin{aligned}
\frac{\partial E[T C U(Q, n)]}{\partial Q}= & -\frac{\left[\left(1+\alpha_{2}\right) K\right] \lambda E_{0}}{Q^{2}}-\frac{n K_{1} \lambda E_{0}}{Q^{2}}+\frac{h(1-E[x])}{2}+\frac{h \lambda E_{1}}{2\left(1+\alpha_{1}\right) P} \\
& +\left(h_{2}-h\right)\left(\frac{1}{2 n}\right)\left[(1-E[x])-\frac{\lambda}{\left(1+\alpha_{1}\right) P}\right]+\frac{h_{2} \lambda}{2\left(1+\alpha_{1}\right) P}=0 \\
\frac{\partial E[T C U(Q, n)]}{\partial n}= & \frac{\lambda K_{1} E_{0}}{Q}+\frac{Q\left(h-h_{2}\right)}{2 n^{2}}\left[(1-E[x])-\frac{\lambda}{\left(1+\alpha_{1}\right) P}\right]=0
\end{aligned}
$$

With further derivatives, optimal production lot size and number of deliveries per cycle can be found as follows: 
Yuan-Shyi Peter Chiu, Han-Ying Chen, Tiffany Chiu, Singa Wang Chiu

$$
Q^{*}=\sqrt{\frac{2 \lambda\left[\left(1+\alpha_{2}\right) K+n K_{1}\right]}{h(1-E[x])^{2}+\frac{h \lambda E[x]}{\left(1+\alpha_{1}\right) P}+\frac{h_{2} \lambda(1-E[x])}{\left(1+\alpha_{1}\right) P}+\frac{\left(h_{2}-h\right) \omega}{n}}}
$$

and

$$
n^{*}=\sqrt{\frac{\left(h_{2}-h\right) K(1+\alpha) \omega}{K_{1}\left[h(1-E[x])^{2}+\frac{h \lambda E[x]}{\left(1+\alpha_{1}\right) P}+\frac{h_{2} \lambda(1-E[x])}{\left(1+\alpha_{1}\right) P}\right]}}
$$

where

$$
\omega=\left[(1-E[x])^{2}-\frac{\lambda(1-E[x])}{\left(1+\alpha_{1}\right) P}\right]
$$

\subsection{Verifications of the obtained results}

Let $\alpha_{1}$ and $\alpha_{2}$ equal to zeros, the proposed FPR-based supply-chain system is converted into a (unadjusted production rate) FPR model with random scraps and multiple deliveries, Eqs. (21) to (23) turn into the following:

$$
Q^{*}=\sqrt{\frac{2 \lambda\left(K+n K_{1}\right)}{h(1-E[x])^{2}+\frac{h \lambda E[x]}{P}+\frac{h_{2} \lambda(1-E[x])}{P}+\frac{\left(h_{2}-h\right) \omega}{n}}}
$$

and

$$
n^{*}=\sqrt{\frac{\left(h_{2}-h\right) K \omega}{K_{1}\left[h(1-E[x])^{2}+\frac{h \lambda E[x]}{P}+\frac{h_{2} \lambda(1-E[x])}{P}\right]}}
$$

where

$$
\omega=\left[(1-E[x])^{2}-\frac{\lambda(1-E[x])}{P}\right]
$$

Moreover, if no scrap items are produced (i.e., $x=0$ ), then the proposed FPR-based supply-chain system is converted into a traditional FPR model as follows:

and

$$
Q^{*}=\sqrt{\frac{2 \lambda\left(K+n K_{1}\right)}{h+\frac{h_{2} \lambda}{P}+\frac{\left(h_{2}-h\right) \omega}{n}}}
$$

where

$$
n^{*}=\sqrt{\frac{\left(h_{2}-h\right) K \omega}{K_{1}\left(h+\frac{h_{2} \lambda}{P}\right)}}
$$


Incorporating Flexible Fabrication Rate and Random Scrap Into A FPR-Based Supply-Chain System

$$
\omega=\left(1-\frac{\lambda}{P}\right)
$$

\section{Numerical example}

Applicability of the proposed FPR-based supply-chain system with flexible manufacture rate, random scrap, and multiple shipments is demonstrated using the following numerical example, in which

$$
\begin{array}{ll}
P & =20,000 \text { products per year, } \\
\lambda & =4,000 \text { products per year, } \\
\alpha_{1} & =0.5, \\
P_{\mathrm{A}} & =30,000 \text { products per year }\left(\text { i.e., }\left(1+\alpha_{1}\right) P\right) \\
x & =[0,0.2], \text { which obeys a uniform distribution, } \\
K & =\$ 5,000 \text { per cycle, } \\
C & =\$ 100 \text { per product, } \\
\alpha_{2} & =0.1\left(\text { i.e. }, 0.2\left(\alpha_{1}\right)\right) \\
K_{\mathrm{A}} & =\$ 5,500\left(\text { i.e. },\left(1+\alpha_{2}\right) K\right) \\
K & =\$ 5,000 \text { per cycle, } \\
\alpha_{3} & =0.25\left(\text { i.e., } 0.5\left(\alpha_{1}\right)\right) \\
C_{\mathrm{A}} & =\$ 125\left(\mathrm{i} . \mathrm{e} .,\left(1+\alpha_{3}\right) C\right) \\
h & =\$ 30, \\
C_{\mathrm{S}} & =\$ 20, \\
K_{1} & =\$ 800 \text { per shipment, } \\
C_{\mathrm{T}} & =\$ 0.5 \text { per product. }
\end{array}
$$

Apply Eqs. (21) and (22), we obtain $n^{*}=3$ and $Q^{*}=1,175$. From computation of Eq. (17), $\mathrm{E}\left[T C U\left(Q^{*}, n^{*}\right)\right]=\$ 626,223$ is found. Further analysis reveals the behavior of different cost components of $\mathrm{E}[\operatorname{TCU}(Q, n)]$ with respect to $Q$, as depicted in Figure 5.

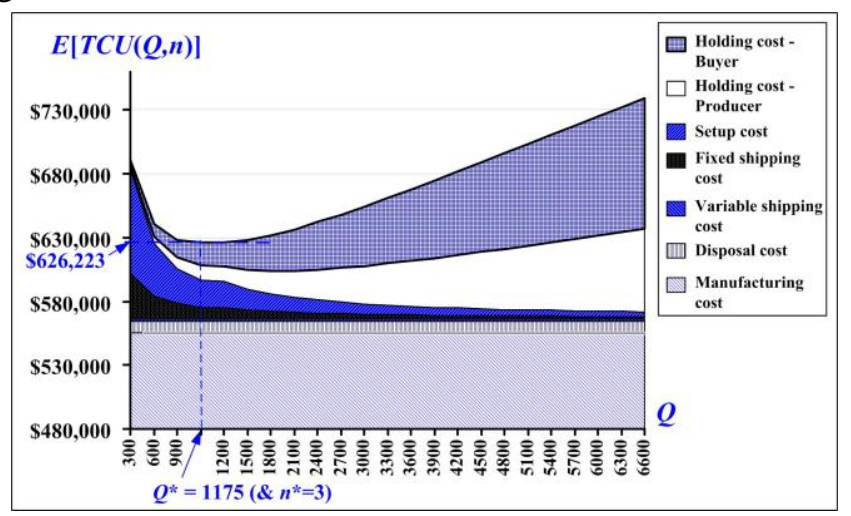

Figure 5. Behavior of different cost components of $\mathrm{E}[T C U(Q, n)]$ with respect to $Q$ It is noted that as $Q$ increases, inventory holding costs at both buyer and producer sides significantly grow; on the contrary, both setup cost and fixed shipping cost 
Yuan-Shyi Peter Chiu, Han-Ying Chen, Tiffany Chiu, Singa Wang Chiu

notably decrease when $Q$ increases. Effect of different scrap rates on total scrap and disposal costs is displayed in Figure 6. It can be seen from Figure 6 that as random scrap rate $x$ increases, total scrap and disposal costs of the proposed model go up significantly.

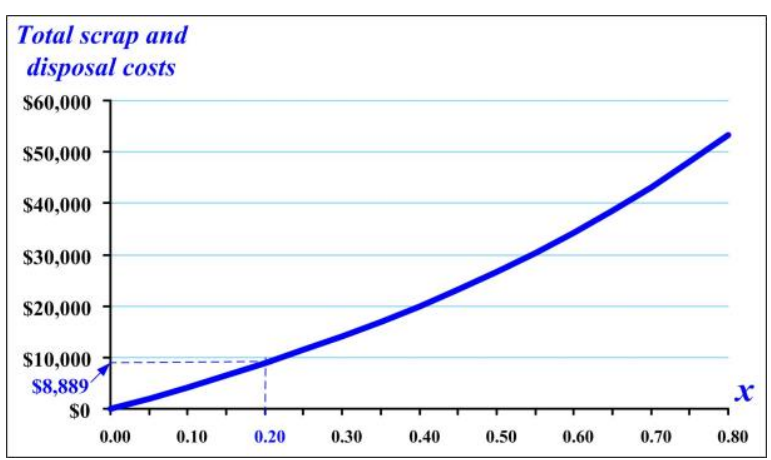

Figure 6. Effect of different scrap rates on total scrap and disposal costs

Figure 7 reveals the joint impact of variations in production lot size $Q$ and number of deliveries per cycle $n$ on the expected total system cost per unit time $E[T C U(Q$, $n)$ ]. It is noted that as both $Q$ and $n$ deviate from $Q^{*}$ and $n^{*}$, the expected total system cost $E[T C U(Q, n)]$ increases accordingly.

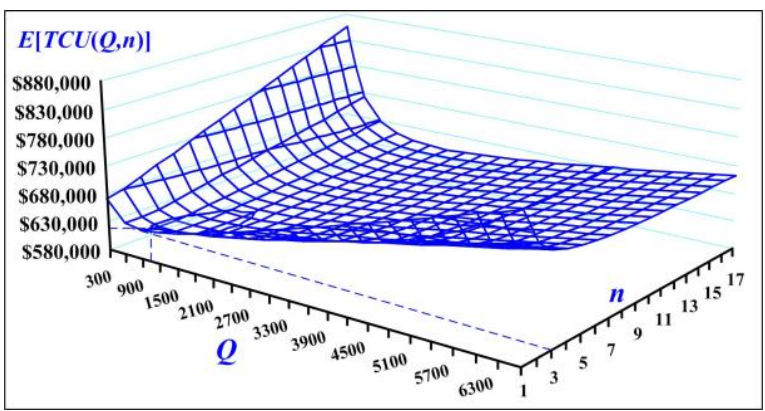

Figure 7. Joint impact of lot size $Q$ and number of deliveries $n$ on $E[T C U(Q, n)]$

Further analysis (see Figure 8) shows that the joint effects of variations in random scrap rate $x$ and production rate adjusted factor $\alpha_{1}$ on $E[T C U(Q, n)]$. 
Incorporating Flexible Fabrication Rate and Random Scrap Into A FPR-Based Supply-Chain System

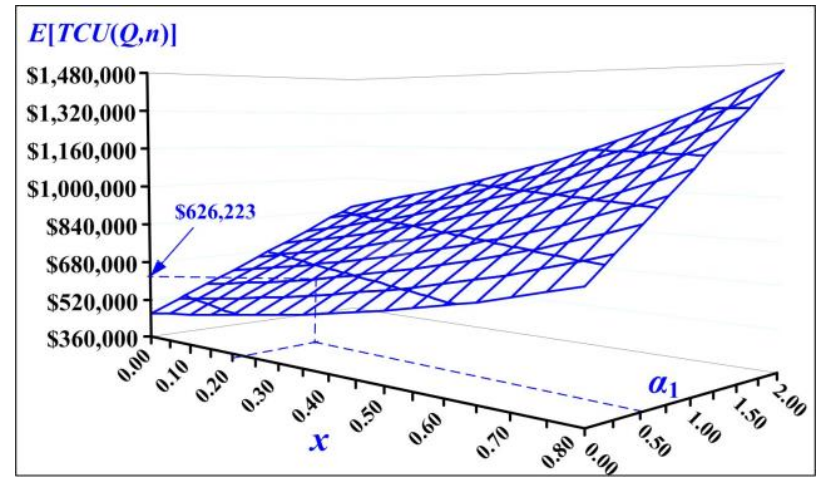

Figure 8. Joint effects of $x$ and production rate adjusted factor $\alpha_{1}$ on $E[T C U(Q, n)]$

It can be seen that as $x$ increases, $E[T C U(Q, n)]$ grows accordingly; and as production rate adjusted factor $\alpha_{1}$ increases, $E[T C U(Q, n)]$ goes up significantly, mainly due to increases in setup and variable production costs. Further analysis reveals the impact of production rate adjusted factor $\alpha_{1}$ on the optimal lot size and number of deliveries (see Table 1).

Table 1. Impact of production rate adjusted factor $\alpha_{1}$ on the optimal $Q^{*}$ and $n^{*}$

\begin{tabular}{cccc}
\hline$\alpha_{1}$ & $Q^{*}$ & $n^{*}$ & $E\left[T C U\left(Q^{*}, n^{*}\right)\right]$ \\
\hline 0 & 979 & 2 & $\$ 515,237$ \\
0.1 & 995 & 2 & $\$ 537,386$ \\
0.2 & 1010 & 2 & $\$ 559,608$ \\
0.3 & 1144 & 2 & $\$ 581,805$ \\
0.4 & 1160 & 2 & $\$ 603,991$ \\
0.5 & 1175 & 3 & $\$ 626,223$ \\
\hline 0.6 & 1189 & 3 & $\$ 648,494$ \\
0.7 & 1202 & 3 & $\$ 670,795$ \\
0.8 & 1215 & 3 & $\$ 693,122$ \\
0.9 & 1227 & 3 & $\$ 715,470$ \\
1.0 & 1239 & 3 & $\$ 737,836$ \\
\hline 1.1 & 1250 & 3 & $\$ 760,218$ \\
1.2 & 1261 & 3 & $\$ 782,613$ \\
1.3 & 1272 & 3 & $\$ 805,020$ \\
1.4 & 1283 & 3 & $\$ 827,435$ \\
1.5 & 1293 & 3 & $\$ 849,860$ \\
\hline 1.6 & 1303 & 3 & $\$ 872,291$ \\
1.7 & 1313 & 3 & $\$ 894,729$ \\
1.8 & 1322 & 3 & $\$ 917,173$ \\
1.9 & 1332 & 3 & $\$ 939,621$ \\
2.0 & 1341 & 3 & $\$ 962,073$ \\
\hline
\end{tabular}

From Table 1, we can obtain the influence of $\alpha_{1}$ on optimal lot size $Q$ and number of deliveries $n$ as depicted in Figure 9. It can be seen from Figure 9 that as 
Yuan-Shyi Peter Chiu, Han-Ying Chen, Tiffany Chiu, Singa Wang Chiu

production rate adjusted factor $\alpha_{1}$ increases, both $Q$ and $n$ grow accordingly, and the optimal $\left(Q^{*}, n^{*}\right)$ policy is at $(1175,3)$, as $\alpha_{1}$ set at 0.50 in our numerical example.

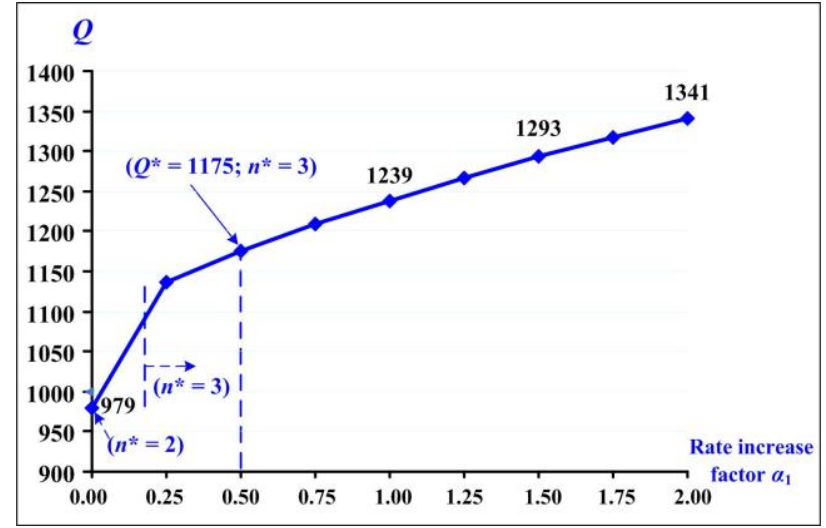

Figure 9. Influence of production rate adjusted factor $\alpha_{1}$ on the optimal $Q$ and $n$

Figure 10 depicts the effect of production rate adjusted factor $\alpha_{1}$ on the machine utilization percentage. It is noted that as production rate adjusted factor $\alpha_{1}$ increases, machine utilization percentage declines considerably, and machine utilization percentage is at $14.8 \%$ as $\alpha_{1}$ set at 0.50 in our numerical example (i.e., utilization reduces $33.3 \%$, from $22.2 \%$ to $14.8 \%$, as production rate adjusts $50 \%$ higher).

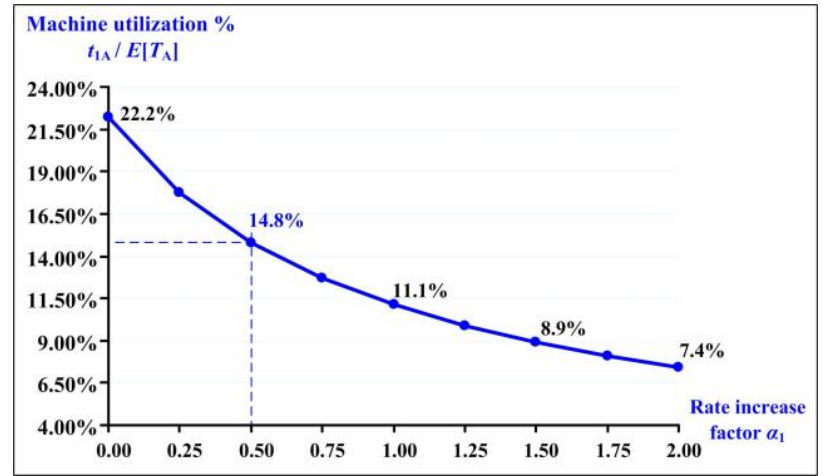

Figure 10. Effect of production rate adjusted factor $\alpha_{1}$ on machine utilization percentage

Moreover, the proposed model enables us to expose the impact of unit production cost increase factor $\alpha_{3}$ on the expected system cost $E[T C U(Q, n)]$ (see Table 2).

Table 2: Impact of unit cost increase factor $\alpha_{3}$ on $E[T C U(Q, n)]$ and its increases \%

\begin{tabular}{ccc}
\hline$\alpha_{3}$ & $E[T C U(Q, n)]$ & increase \% \\
\hline 0 & $\$ 515,237$ & - \\
0.05 & $\$ 537,386$ & $4.30 \%$ \\
0.10 & $\$ 559,608$ & $8.61 \%$ \\
\hline
\end{tabular}


Incorporating Flexible Fabrication Rate and Random Scrap Into A FPR-Based Supply-Chain System

\begin{tabular}{lll}
\hline 0.15 & $\$ 581,805$ & $12.92 \%$ \\
0.20 & $\$ 603,991$ & $17.23 \%$ \\
0.25 & $\$ 626,223$ & $21.54 \%$ \\
\hline 0.30 & $\$ 648,494$ & $25.86 \%$ \\
0.35 & $\$ 670,795$ & $30.19 \%$ \\
0.40 & $\$ 693,122$ & $34.52 \%$ \\
0.45 & $\$ 715,470$ & $38.86 \%$ \\
0.50 & $\$ 737,836$ & $43.20 \%$ \\
\hline 0.55 & $\$ 760,218$ & $47.55 \%$ \\
0.60 & $\$ 782,613$ & $51.89 \%$ \\
0.65 & $\$ 805,020$ & $56.24 \%$ \\
0.70 & $\$ 827,435$ & $60.59 \%$ \\
0.75 & $\$ 849,860$ & $64.95 \%$ \\
\hline 0.80 & $\$ 872,291$ & $69.30 \%$ \\
0.85 & $\$ 894,729$ & $73.65 \%$ \\
0.90 & $\$ 917,173$ & $78.01 \%$ \\
0.95 & $\$ 939,621$ & $82.37 \%$ \\
1.00 & $\$ 962,073$ & $86.72 \%$ \\
\hline
\end{tabular}

From Table 2, we can obtain the behavior of $E[T C U(Q, n)]$ with respect to unit production cost increase factor $\alpha_{3}$ (as shown in Figure 11). It can be seen that as $\alpha_{3}$ increases, $E[T C U(Q, n)]$ goes up notably. In our numerical example, as $\alpha_{3}$ set at 0.25 , the expected system cost $E[T C U(Q, n)]$ grows $21.54 \%$.

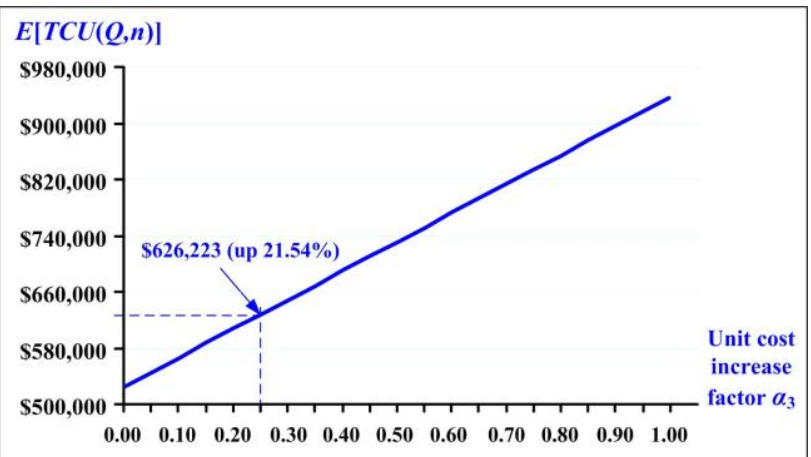

Figure 11. Behavior of $E[T C U(Q, n)]$ with respect to unit cost increase factor $\alpha_{3}$

\section{Conclusions}

A specific FPR-based supply-chain system is built and explored with the purpose of helping management of the manufacturing firms to reduce fabrication cycle length, assure product quality, and cut down product shipping expenses. Optimization techniques are employed to resolve the problem. The optimal lot size and number of shipments per cycle are determined. Applicability of the research results are verified via a numerical example. 
Yuan-Shyi Peter Chiu, Han-Ying Chen, Tiffany Chiu, Singa Wang Chiu

Sensitivity analyses of the proposed system enable production managers to reveal different critical system information for supporting their decision makings. Such information includes (1) effect of lot-size and scrap rate on expected system cost (Figs. 5-6); (2) joint influence of lot-size and number of shipments on expected system cost (Fig. 7); (3) joint effects of scrap rate and production rate adjusted factor $\alpha_{1}$ on expected system cost (Fig. 8); (4) impact of production rate adjusted factor $\alpha_{1}$ on optimal lot-size and number of shipments (Fig. $9 \&$ Table 1); (5) effect of production rate adjusted factor $\alpha_{1}$ on machine utilization (Fig. 10); (6) the behavior of expected system cost with respect to unit cost increase factor $\alpha_{3}$ (Table 2 \& Fig. 11); etc. Furthermore, the proposed study can also incorporate the likely machine maintenance cost increase as well as the potential benefits gained due to expedited/adjusted fabrication rate (see the conceptual effect of utilization decrease on the benefit/cost of the proposed system as shown in Figure 12).

In summary, without an in-depth investigation (like the proposed study has done), none of the aforementioned critical system information of this specific FPR-based supply-chain system is accessible to production managers. For future study, examining the effect of reworking nonconforming items on the optimal operating policy to the same problem could be an interesting subject.

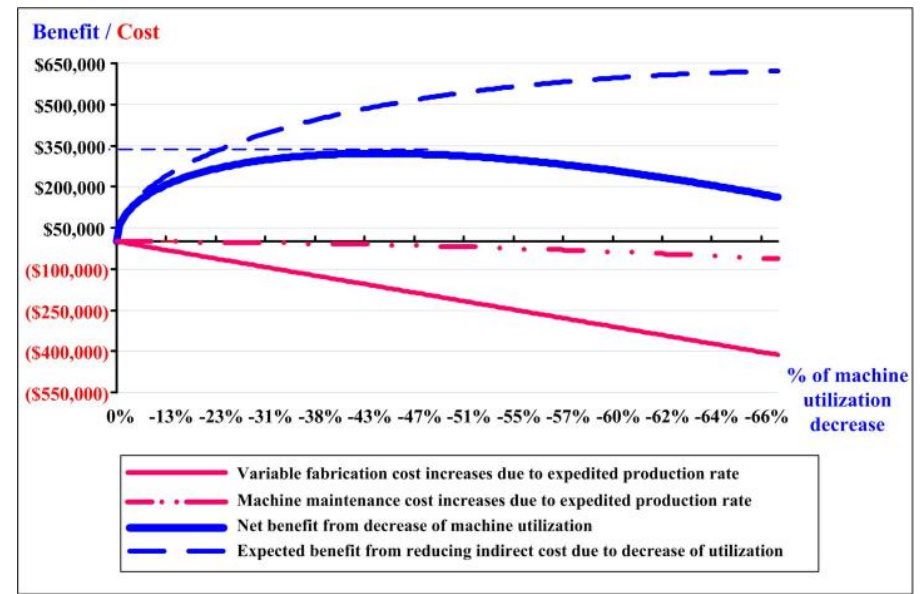

Figure 12. The effect of utilization decrease on benefit/cost of the proposed system

\section{ACKNOWLEDGMENTS}

This research was supported by the Ministry of Science and Technology (MOST) of Taiwan, under project no. MOST 104-2410-H-324-008-MY2. 
Incorporating Flexible Fabrication Rate and Random Scrap Into A FPR-Based Supply-Chain System

Appendix A - Nomenclature

\begin{tabular}{|c|c|}
\hline Notation & Definition \\
\hline$\lambda$ & Annual demand rate of the proposed FPR-based supply chain system \\
\hline$Q$ & Lot size per cycle of the proposed system - one of the decision variables \\
\hline$n$ & Number of deliveries per cycle - the other decision variable \\
\hline$T_{\mathrm{A}}$ & Cycle time of the proposed system \\
\hline$t_{1 \mathrm{~A}}$ & Uptime \\
\hline$t_{2 \mathrm{~A}}$ & Downtime (or distribution time) \\
\hline$t_{\mathrm{nA}}$ & Interval of time between two consecutive deliveries in $t_{2 \mathrm{~A}}$ \\
\hline$P_{\mathrm{A}}$ & Adjusted production rate of the proposed system \\
\hline$P$ & Standard production rate in the conventional FPR model \\
\hline$\alpha_{1}$ & Adjusted percentage of production rate \\
\hline$K_{\mathrm{A}}$ & Adjusted setup cost based on the adjusted production rate in the proposed system \\
\hline$K$ & Standard setup cost \\
\hline$\alpha_{2}$ & Adjusted proportion of setup cost in the proposed system \\
\hline$C_{\mathrm{A}}$ & Adjusted unit production cost in the proposed system \\
\hline$C$ & Standard unit production cost \\
\hline$\alpha_{3}$ & Adjusted proportion of unit production cost in the proposed system \\
\hline$x$ & Random scrap rate during production process in the proposed system \\
\hline$d_{\mathrm{A}}$ & Fabrication rate of scrap items in the proposed system \\
\hline$h$ & Unit holding cost per year \\
\hline$C_{\mathrm{S}}$ & Unit disposal cost per scrapped item \\
\hline$K_{1}$ & Fixed cost per delivery \\
\hline$C_{\mathrm{T}}$ & Unit distribution cost \\
\hline$D$ & Number of finished products per delivery \\
\hline I & the leftover stocks in the end of each $t_{\mathrm{nA}}$, after demand $\lambda t_{\mathrm{nA}}$ is satisfied \\
\hline$E\left[T_{\mathrm{A}}\right]$ & The expected cycle time of the proposed system \\
\hline$T C(Q, n)$ & Total system cost per cycle of the proposed system \\
\hline$E[T C U(Q, n)]$ & The expected total system cost per unit time in the proposed system \\
\hline$I(t)$ & On-hand inventory level of perfect quality products at time $t$ \\
\hline$I_{\mathrm{d}}(t)$ & On-hand inventory level of scrap items at time $t$ \\
\hline$d$ & Production rate of scrap items in the traditional model \\
\hline$t_{1}$ & Uptime in traditional FPR model \\
\hline$t_{2}$ & Downtime in traditional FPR model \\
\hline$t_{\mathrm{n}}$ & Interval of time between two consecutive deliveries in traditional FPR model \\
\hline$T$ & Cycle time in traditional FPR model \\
\hline
\end{tabular}


Yuan-Shyi Peter Chiu, Han-Ying Chen, Tiffany Chiu, Singa Wang Chiu

Appendix B - Hessian matrix equations

Apply the Hessian matrix equations [25], we first obtain the following:

$$
\begin{aligned}
& \frac{\partial E[T C U(Q, n)]}{\partial Q}=-\frac{\left[\left(1+\alpha_{2}\right) K\right] \lambda E_{0}}{Q^{2}}-\frac{n K_{1} \lambda E_{0}}{Q^{2}}+\frac{h(1-E[x])}{2}+\frac{h \lambda E_{1}}{2\left(1+\alpha_{1}\right) P} \\
& +\left(h_{2}-h\right)\left(\frac{1}{2 n}\right)\left[(1-E[x])-\frac{\lambda}{\left(1+\alpha_{1}\right) P}\right]+\frac{h_{2} \lambda}{2\left(1+\alpha_{1}\right) P} \\
& \frac{\partial^{2} E[T C U(Q, n)]}{\partial Q^{2}}=\frac{2\left[\left(1+\alpha_{2}\right) K\right] \lambda E_{0}}{Q^{3}}+\frac{2 n K_{1} \lambda E_{0}}{Q^{3}} \\
& \frac{\partial E[T C U(Q, n)]}{\partial n}=\frac{\lambda K_{1} E_{0}}{Q}+\frac{Q\left(h-h_{2}\right)}{2 n^{2}}\left[(1-E[x])-\frac{\lambda}{\left(1+\alpha_{1}\right) P}\right] \\
& \frac{\partial^{2} E[T C U(Q, n)]}{\partial n^{2}}=\frac{-Q\left(h-h_{2}\right)}{n^{3}}\left[(1-E[x])-\frac{\lambda}{\left(1+\alpha_{1}\right) P}\right] \\
& \frac{\partial E[T C U(Q, n)]}{\partial Q \partial n}=\frac{-\lambda K_{1} E_{0}}{Q^{2}}+\frac{\left(h-h_{2}\right)}{2 n^{2}}\left[(1-E[x])-\frac{\lambda}{\left(1+\alpha_{1}\right) P}\right]
\end{aligned}
$$

Substitute Eqs. (A-1) to (A-5) in Hessian matrix equations and with extra derivations, we obtain the following:

$$
\left[\begin{array}{ll}
Q & n
\end{array}\right] \cdot\left(\begin{array}{ll}
\frac{\partial^{2} E[T C U(Q, n)]}{\partial Q^{2}} & \frac{\partial^{2} E[T C U(Q, n)]}{\partial Q \partial n} \\
\frac{\partial^{2} E[T C U(Q, n)]}{\partial Q \partial n} & \frac{\partial^{2} E[T C U(Q, n)]}{\partial n^{2}}
\end{array}\right) \cdot\left[\begin{array}{l}
Q \\
n
\end{array}\right]=\frac{2\left[\left(1+\alpha_{2}\right) K\right] \lambda E_{0}}{Q}
$$

\section{REFERENCES}

[1] Taft, E.W. (1918), The Most Economical Production Lot. Iron Age 101, 1410-1412;

[2] Buzacott, J.A., Ozkarahan, I.A. (1983), One- and Two-Stage Scheduling of Two Products with Distributed Inserted Idle Time: The Benefits of a Controllable Production Rate. Naval research logistics quarterly 30(4), 675-696;

[3] Gallego, G. (1993), Reduced Production Rates in the Economic Lot Scheduling Problem. International Journal of Production Research 31(5), 1035-1046;

[4] Eynan, A. (2003), The Benefits of Flexible Production Rates in the Economic Lot Scheduling Problem. IIE Transactions 35(11), 1057-1064;

[5] Glock, C.H. (2010), Batch Sizing with Controllable Production Rates. International Journal of Production Research 48(20), 5925-5942; 
Incorporating Flexible Fabrication Rate and Random Scrap Into A FPR-Based Supply-Chain System

[6] Farzam Rad, M., Sajadi, S.M., Hosseinzadeh Kashan, A. (2015), Determination of Optimal Production Rate in Stochastic Manufacturing Systems by Simulation Optimization Approach. International Journal of Industrial and Systems Engineering 20(3), 306-322;

[7] Giri, B.C., Dohi, T. (2005), Computational Aspects of an Extended EMQ Model with Variable Production Rate. Computers and Operations Research 32(12), 3143-3161;

[8] Sharma, S. (2011), Effects Concerning Quality Level with the Increase in Production Rate. International Journal of Advanced Manufacturing Technology 53(5-8), 629-634;

[9] Sajadieh, M.S., Larsen, C. (2015), A Coordinated Manufacturer-Retailer Model under Stochastic Demand and Production Rate. International Journal of Production Economics 168, 64-70;

[10] Schwaller, R. (1988), EOQ under Inspection Costs. Production and Inventory Management, 29, 22-24;

[11] Cheung K. L., Hausman, W. H. (1997), Joint Determination of Preventive Maintenance and Safety Stocks in an Unreliable Production Environment. Naval Research Logistics 44(3), 257-272;

[12] Ritvirool, A., Ferrell Jr., W. G. (2007), The Effect on Inventory of Cooperation in Single-Vendor, Single-Buyer Systems with Quality Considerations. International Journal of Operational Research 2(3), 338-356;

[13] Chiu, Y-S.P., Chiang, K-W., Chiu, S.W., Song, M-S. (2016), Simultaneous Determination of Production and Shipment Decisions for a Multi-Product Inventory System with a Rework Process. Advances in Production Engineering \& Management 11(2), 141-151;

[14] Jindal, P., Solanki, A. (2016), Integrated Supply Chain Inventory Model with Quality Improvement Involving Controllable Lead Time and Backorder Price Discount. International Journal of Industrial Engineering Computations 7(3), 463-480;

[15] Makarova, I., Shubenkova, K., Mavrin, V., Boyko, A. (2017), Ways to Increase Sustainibility of the Transportation System. Journal of Applied Engineering Science 15(1), 89-98;

[16] Michalski, G. (2016), Risk Pressure and Inventories Levels. Influence of Risk Sensitivity on Working Capital Levels. Economic Computation and Economic Cybernetics Studies and Research 50(1), 189-196;

[17] Kohli, R., Park, H. (1994), Coordinating Buyer-seller Transactions across Multiple Products. Management Science 40(9), 45-50;

[18] Sarker, R. A., Khan, L. R. (2001), An Optimal Batch Size under a Periodic Delivery Policy. International Journal of Systems Science 32(9), 1089-1099;

[19] Giri, B. C., Chakraborty, A. (2011), Supply Chain Coordination for a Deteriorating Product under Stock- Dependent Consumption Rate and Unreliable Production Process. International Journal of Industrial Engineering Computations 2(2), 263-272; 
Yuan-Shyi Peter Chiu, Han-Ying Chen, Tiffany Chiu, Singa Wang Chiu

[20] Cao, J., Chen, Y., Zhou, G. (2015), A Novel Statistical Prediction Technique Based on the Dynamic Relationship Identification Algorithm to Forecast Supply Chain Demand. Economic Computation and Economic Cybernetics Studies and Research 49(1), 203-222;

[21] Chiu, Y-S. P., Kuo, J-S., Chiu, S. W., Hsieh, Y-T. (2016), Effect of Delayed Differentiation on a Multi-Product Vendor-Buyer Integrated Inventory System with Rework. Advances in Production Engineering \& Management 11(4), 333-344;

[22] Florea, A.I., Corbos, R., Popescu, R.I., Zamfir, A. (2016), From the Factory Floor to the Shop Floor - Improved Supply Chain for Sustainable Competitive Advantage with Item-Level RFID in Retail. Economic Computation and Economic Cybernetics Studies and Research 50(4), 119-134;

[23] Khalili, A., Ismail, M. Y., Karim, A. N. M., Che Daud, M. R. (2017), Critical Success Factors for Soft TQM and Lean Manufacturing Linkage. Jordan Journal of Mechanical and Industrial Engineering 11(2), 129-140;

[24] Chiu, S.W., Liu, C.-J., Li, Y.-Y., Chou, C.-L. (2017), Manufacturing Lot Size and Product Distribution Problem with Rework, Outsourcing and Discontinuous Inventory Distribution Policy. International Journal for Engineering Modelling 30(1-4), 49-61;

[25] Rardin, R. L. (1998), Optimization in Operations Research. Prentice-Hall, New Jersey, 739-741. 